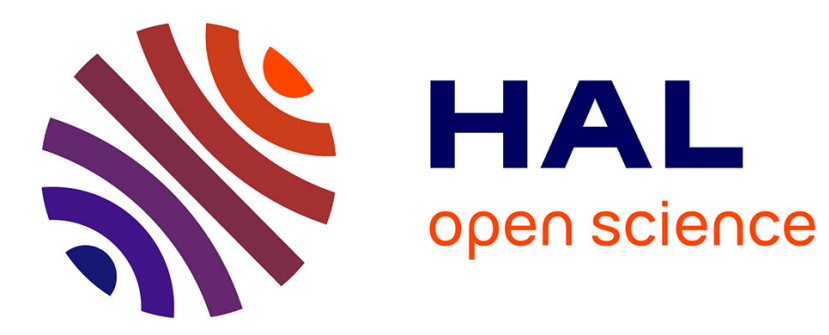

\title{
L-Selectin-deficient SJL and C57BL/6 mice are not resistant to experimental autoimmune encephalomyelitis.
}

Chiara Uboldi, Axinia Döring, Carsten Alt, Pila Estess, Mark Siegelman, Britta Engelhardt

\section{- To cite this version:}

Chiara Uboldi, Axinia Döring, Carsten Alt, Pila Estess, Mark Siegelman, et al.. L-Selectin-deficient SJL and C57BL/6 mice are not resistant to experimental autoimmune encephalomyelitis.. European Journal of Immunology, 2008, 38 (8), pp.2156-2167. 10.1002/eji.200838209 hal-02355407

\section{HAL Id: hal-02355407 https://hal.science/hal-02355407}

Submitted on 8 Nov 2019

HAL is a multi-disciplinary open access archive for the deposit and dissemination of scientific research documents, whether they are published or not. The documents may come from teaching and research institutions in France or abroad, or from public or private research centers.
L'archive ouverte pluridisciplinaire HAL, est destinée au dépôt et à la diffusion de documents scientifiques de niveau recherche, publiés ou non, émanant des établissements d'enseignement et de recherche français ou étrangers, des laboratoires publics ou privés. 


\title{
L-Selectin-deficient SJL and C57BL/6 mice are not resistant to experimental autoimmune encephalomyelitis
}

\author{
Chiara Uboldi ${ }^{1,2}$, Axinia Döring ${ }^{1}$, Carsten Alt $^{2}$, Pila Estess ${ }^{3}$, Mark Siegelman ${ }^{3}$ \\ and Britta Engelhardt ${ }^{1}$
}

1 Theodor Kocher Institute, University of Bern, Bern, Switzerland

2 Max-Planck Institute for Molecular Biomedicine, Münster, Germany

${ }^{3}$ University Texas Southwestern, Dallas, TX, USA

L-selectin has been suggested to play a role in the pathogenesis of experimental autoimmune encephalomyelitis (EAE), an animal model of multiple sclerosis. Here we demonstrate that L-selectin ${ }^{-/}$SJL mice are susceptible to proteolipid protein (PLP)-induced EAE because the compromised antigen-specific $\mathrm{T}$ cell proliferation in peripheral lymph nodes is fully compensated by the $\mathrm{T}$ cell response raised in their spleen. Transfer of PLPspecific $\mathrm{T}$ cells into syngeneic recipients induced $\mathrm{EAE}$ independent of the presence or absence of L-selectin on PLP-specific T cells or in the recipient. Leukocyte infiltration into the central nervous system parenchyma was detectable independent of the mode of disease induction and the presence or absence of L-selectin. In addition, we found L-selectin ${ }^{-/}$ C57BL/ 6 mice to be susceptible to myelin oligodendrocyte glycoprotein-induced EAE. Taken together, we demonstrate that in SJL and C57BL/6 mice L-selectin is not required for EAE pathogenesis. The apparent discrepancy of our present observation to previous findings, demonstrating a role of L-selectin in EAE pathogenesis in C57BL/6 mice or myelin-basic protein (MBP)-specific TCR-transgenic B10.PL mice, may be attributed to background genes rather than L-selectin and to a unique role of L-selectin in EAE pathogenesis in MBP-TCRtransgenic mice.

Key words: C57BL/6 mouse - Experimental autoimmune encephalomyelitis · L-Selectin . SJL mouse · Lymphocyte trafficking

\section{Introduction}

In multiple sclerosis (MS), and in its animal model, experimental autoimmune encephalomyelitis (EAE), circulating immune cells gain access to the CNS and cause inflammation, blood-brain barrier (BBB) breakdown and demyelination, all of which set the stage for the development of the clinical manifestations of this disabling disease. EAE is a T cell-mediated autoimmune disease, which can be either actively induced (aEAE) by immunization with myelin antigens or by the transfer of encephalitogenic myelinspecific $\mathrm{T}$ cells in susceptible rodents including several mouse strains. In the SJL mouse, EAE is mostly induced by immunization with a proteolipid protein (PLP) peptide (amino acids 139-151, $\mathrm{PLP}_{\mathrm{aa} 139-151}$ ) or the adoptive transfer of the respective PLP-specific $\mathrm{CD}^{+} \mathrm{T}$ cell blasts into syngeneic recipients. Similarly, in the C57BL/ 6 mouse, EAE is most commonly induced by immunization with a myelin oligodendrocyte glycoprotein (MOG) peptide (amino acids 35-55, MOG ${ }_{\mathrm{aa} 35-55}$ ) or by the adoptive transfer of the respective MOG-specific $\mathrm{CD}^{+}{ }^{+} \mathrm{T}$ cell blasts into - usually sublethally irradiated - syngeneic recipients. Interaction of circulating immunocompetent cells with the BBB endothelium is a critical step in the pathogenesis of CNS inflammation during EAE.

The recruitment of specific leukocyte subsets from the blood stream into distinct tissues is mediated by the sequential 
interaction of different adhesion and signaling molecules on leukocytes and the endothelial cells lining the vessel wall (reviewed by [1]). The multi-step interaction starts with an initial transient contact of the circulating leukocyte with the vascular endothelium, mediated by adhesion molecules of the selectin family and their respective carbohydrate ligands, or by $\alpha 4$ integrins. After the initial tether, the leukocyte rolls along the vascular wall with greatly reduced velocity. The rolling leukocyte can then bind chemotactic factors from the family of chemokines presented on the endothelial surface. Chemokines bind to serpentine receptors on the leukocyte surface delivering a $\mathrm{G}$ protein-mediated inside-out signal to integrins present on the leukocyte surface, thereby enhancing their avidity. Only integrins with increased avidity are able to mediate the firm adhesion of the leukocytes to the vascular endothelium by binding to their endothelial ligands of the immunoglobulin (Ig) superfamily. This ultimately leads to diapedesis of the leukocyte.

It is generally accepted that $\alpha 4$ integrins play a predominant role in T cell trafficking across the BBB during EAE, as they mediate both $\mathrm{T}$ cell rolling and firm adhesion of $\mathrm{T}$ cells to the BBB (summarized in [2]). In contrast, the adhesion molecules generally mediating leukocyte rolling along the vascular wall, such as P-selectin glycoprotein ligand (PSGL-1) [3, 4] or its endothelial ligands $\mathrm{E}$ - and P-selectin, are not required for the development of EAE in C57BL/6 and SJL mice [5, 6]. Similarly, L-selectin has been shown in antibody blocking experiments to play no role in the recruitment of inflammatory cells across the BBB during EAE [7]; nevertheless, its role in EAE pathogenesis remains controversial $[8,9]$.

L-selectin was first described as the peripheral lymph node (PLN)-homing receptor, defined by the mAb Mel 14, which blocks T cell rolling on high endothelial venules in PLN $[10,11]$. Later, it was discovered that L-selectin is expressed on almost all leukocyte subpopulations including neutrophils and monocytes/macrophages. Thus, besides its role in immunosurveillance, L-selectin has been shown to mediate inflammatory cell recruitment to a variety of sites of inflammation (summarized in [12]). In addition, studies performed in L-selectin-deficient mice have demonstrated an involvement of L-selectin in the generation of primary $\mathrm{T}$ cell responses $[13,14]$, suggesting a potential role of L-selectin in the development of autoimmune diseases.

As mentioned above, investigations on the role of L-selectin in EAE pathogenesis have produced controversial results. Antibody inhibition studies performed in passive transfer EAE models in the Lewis rat or the (PLxSJL) $F_{1}$ mouse failed to demonstrate any role of L-selectin in EAE pathogenesis [7, 15]. In contrast, anti-Lselectin antibodies block the development of aEAE in the Lewis rat [15]. Furthermore, L-selectin-deficient C57BL/6 mice were reported to be resistant to EAE due to the failure of encephalitogenic T cell priming [8], whereas L-selectin-deficient myelin-basic protein (MBP)-specific TCR transgenic B10.PL mice failed to develop clinical EAE due to a requirement of L-selectin for effector functions of CNS inflammatory cells [9].

To obtain more insight into the role of L-selectin in EAE pathogenesis we decided to investigate its role in EAE pathogenesis in the SJL mouse model, which allows both the induction of active EAE by immunization with myelin antigen and adoptive transfer of EAE with PLP-specific CD ${ }^{+}$T cells without further manipulation of the mice such as sublethal irradiation as required in the C57BL/6 mouse model. Furthermore, studies in the SJL EAE models have allowed the definition of the role of $\alpha 4$ integrins in inflammatory cell trafficking across the BBB [16, 17], a finding that has been translated into a novel therapy for relapsingremitting MS with the anti- $\alpha 4$ integrin antibody natalizumab. We have backcrossed L-selectin-deficient mice for at least 11 and up to 18 generations into the SJL background. Here, we show that $\mathrm{L}-$-selectin $^{-1-}$ SJL mice are neither resistant to active EAE induced

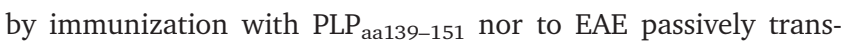
ferred by PLP-specific T cells. Furthermore, L-selectin is not required on PLP-specific T cells to transfer EAE or on inflammatory cells to enter the CNS parenchyma. Additionally, we have backcrossed L-selectin-deficient mice for 18 generations into the C57BL/ 6 background and found that these mice are susceptible to EAE. Thus, in the C57BL/ 6 as in the SJL mouse L-selectin is neither required for immune cell trafficking to the CNS nor for the priming, clonal expansion and effector function of encephalitogenic T cells. Our results suggest that the previously reported role of L-selectin in establishing clinical EAE is unique to MBP-TCR B10.PL mice [9] and that sufficient backcrossing is required to be able to distinguish a role of L-selectin from that of other mouse background genes in EAE pathogenesis.

\section{Results}

\section{Anti-L-selectin antibody Mel-14 does not inhibit aEAE in the SJL mouse}

It has been reported that anti-L-selectin antibodies block aEAE, but fail to inhibit adoptively transferred EAE. Antibody inhibition studies were performed to test whether treatment of SJL mice with the anti-L-selectin antibody Mel-14 blocks aEAE induced by immunization of SJL mice with PLP ${ }_{\text {aa139-151 }}$ in CFA. Interestingly, despite detectable serum levels of the antibody, Mel-14 failed to exert any influence on the development of aEAE in the SJL mouse model (Table 1).

\section{Characterization of L-selectin-deficient SJL mice}

As L-selectin-deficient MBP-specific TCR transgenic B10.PL mice and L-selectin-deficient C57BL/6 mice are reported to be resistant to EAE $[8,9]$, we anticipated that development of EAE might only be impaired in the complete absence of L-selectin. L-selectindeficient mice were therefore backcrossed to the EAE-susceptible genetic background of the SJL strain for at least 11 generations before being analyzed and used in the experiments described. To ascertain that the phenotype of L-selectin-deficient mice described in the $129 / \mathrm{Sv} / / \mathrm{C} 57 \mathrm{BL} / 6$ chimeric genetic background [14] is maintained in the SJL background, lymphoid organ architecture 
Table 1. Mel-14 does not influence the development of aEAE in SJL mice

\begin{tabular}{lll}
\hline aEAE & $\begin{array}{l}\text { Control } \\
\text { antibody }^{\mathrm{a}}\end{array}$ & Mel-14 \\
\hline $\begin{array}{l}\text { No. of SJL/N mice } \\
\begin{array}{l}\text { No. of SJL/N mice with clinical } \\
\text { disease }\end{array}\end{array}$ & 4 & 4 \\
Mean day of onset of disease & $15.3 \pm 1.5$ & $15.7 \pm 1.4$ \\
Mean severity of disease & $2.6 \pm 1.5$ & $2.5 \pm 1.8$ \\
\hline
\end{tabular}

a) Antibody, $400 \mu \mathrm{g}$, was injected i.v. at day -1 before induction of EAE and at days 4 and 10 after induction of EAE. Presence of saturating antibody titers was confirmed by FACS analysis on PLN lymphocytes. One representative experiment out of three is shown.

was investigated by immunohistochemistry and lymphocyte numbers were determined. Reproducing the phenotype published for L-selectin $^{-/-}$mice in the chimeric background [14], mesenteric lymph nodes (MLN) of L-selectin ${ }^{-1-}$ SJL mice were found to resemble those of wild-type mice (data not shown and Table 2). As reported previously, PLN, i.e., popliteal, inguinal, para-aortical, axillary and cervical LN, were strikingly smaller in size (data not shown) and significantly depleted for lymphocytes (Table 2). In contrast, the spleens of L-selectin ${ }^{-/-}$SJL mice were enlarged and harbored a significantly increased number of lymphocytes, when compared to wild type SJL mice (Table 2). Additionally, L-selectin deficiency in the SJL background lead to an apparently increased number of lymphocytes circulating in the blood stream when compared to wild-type SJL mice, which was found to be not significant (Table 2). To address, whether lack of L-selectin expression affects the cell surface expression of adhesion molecules that have previously been demonstrated to be involved in EAE pathogenesis, we investigated the surface expression of $\alpha 4 \beta 1$ - and $\alpha 4 \beta 7$-integrin and LFA- 1 on T lymphocytes isolated from MLN and PLN as well as the spleen. We did not detect any significant differences between wild-type SJL and L-selectin ${ }^{-/-}$SJL mice (data not shown).

\section{L-selectin deficient SJL mice develop EAE upon adoptive transfer with wild-type PLP-specific T cells}

We next asked whether the transfer of PLP-specific CD4 ${ }^{+} \mathrm{T}$ cells

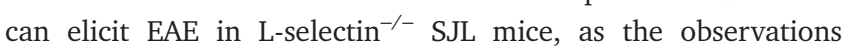
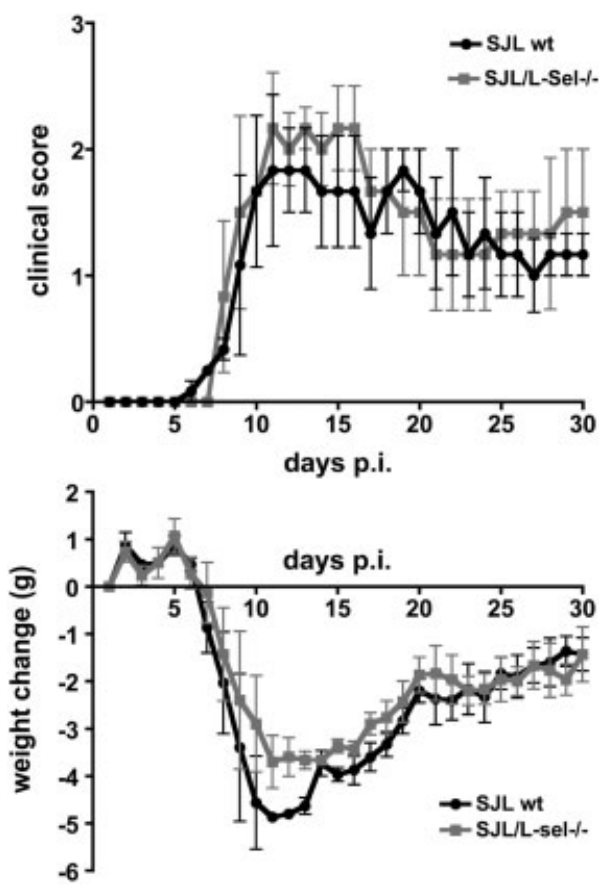

Figure 1. PLP-specific wild-type (wt) T cells transfer EAE into syngeneic wild-type and L-selectin-deficient SJL mice. Average disease scores $\pm S D$ (top panel) and average weight change \pm SD (bottom panel) assessed daily following transfer of encephalitogenic $\mathrm{T}$ cell blasts are shown. Values represent 3 mice per group. One representative experiment out of four with a total number of 14 mice examined per group is shown.

reported in the L-selectin-deficient MBP-TCR transgenic B10.PL mouse and C57BL/ 6 mouse EAE models are contradictory in this issue $[8,9]$. The transfer of freshly activated encephalitogenic $\mathrm{T}$ cells from PLP-specific CD4 ${ }^{+}$Th1 cell lines induced EAE in L-selectin $^{-/-}$SJL mice in a manner indistinguishable from wildtype SJL mice (Fig. 1). Furthermore, we did not observe any difference in the size and cellular composition $\left(\mathrm{CD}^{+} \mathrm{T}\right.$ cells, $\mathrm{B} 220^{+}$B cells, Mac- $1^{+}$macrophages, $\mathrm{CD}^{+} \mathrm{T}$ cells) of the inflammatory cuffs in frozen sections of brains and spinal cords of wild-type and L-selectin ${ }^{-1-}$ SJL mice during EAE. Thus, expression of L-selectin in the host is not required for the development of clinical EAE in SJL mice.

Table 2. Numbers of lymphocytes present in peripheral blood, LN and spleen of SJL wild-type and SJL/L-Sel ${ }^{-/-}$mice

\begin{tabular}{llll}
\hline & SJL/L-sel ${ }^{-/-}$ & SJL wild type & Statistical significance \\
\hline Blood $^{\text {a) }}$ & $2.3 \pm 0.8 \times 10^{7}$ & $1.3 \pm 0.7 \times 10^{7}$ & Not significant \\
MLN $^{\text {a) }}$ & $67 \pm 3 \times 10^{5}$ & $55 \pm 13 \times 10^{5}$ & Not significant \\
PLN & $1.6 \pm 0.95 \times 10^{5}$ & $44.7 \pm 14 \times 10^{5}$ & $p=0.0015$ very significant \\
Spleen & $4.1 \pm 0.4 \times 10^{8}$ & $1.9 \pm 0.6 \times 10^{8}$ & $p=0.0095$ very significant \\
\hline
\end{tabular}

a) Mononuclear cell numbers calculated per mL blood or per lymphoid organ are given. Cell counts were obtained from seven mice per group. Statistical comparison was performed using an unpaired Student's t-test 


\section{Encephalitogenic T cells up-regulate L-selectin expression in vivo}

It has been reported that encephalitogenic $\mathrm{T}$ cells change their surface phenotype in vivo [18]. Thus, although encephalitogenic $\mathrm{T}$ cell blasts transferring EAE do not display any cell surface expression of L-selectin in vitro (Fig. 2), they might up-regulate expression of L-selectin in vivo. L-selectin could thus still be required on encephalitogenic effector $\mathrm{T}$ cells to successfully transfer EAE into syngeneic recipients. To address this, CellTrack$\mathrm{er}^{\mathrm{TM}}$ Green-labeled encephalitogenic T cell blasts were intravenously injected into SJL mice and at 48 and $72 \mathrm{~h}$ after injection spleen, MLN and PLN were harvested and cell suspensions were stained with Mel-14 to detect surface expression of L-selectin. Due to the low number of encephalitogenic T cells homing to the brain and spinal cord early after injection, cell surface expression of $\mathrm{L}$-selectin on the injected encephalitogenic $\mathrm{T}$ cells from these organs could not be determined. However, L-selectin expression could clearly be detected on a low percentage of CellTracker ${ }^{\mathrm{TM}}$ Green-stained encephalitogenic $\mathrm{T}$ cells present in the different secondary lymphoid organs already $48 \mathrm{~h}$ after infusion. By $72 \mathrm{~h}$ after infusion all CellTracker ${ }^{\mathrm{TM}}$ Green-positive encephalitogenic $\mathrm{T}$ cells present in PLN and significant subpopulations of these T cells present in MLN and the spleen stained positive for L-selectin (Fig. 2). PLP-specific T cells grown in vitro remained negative for L-selectin cell surface staining throughout this time (not shown).

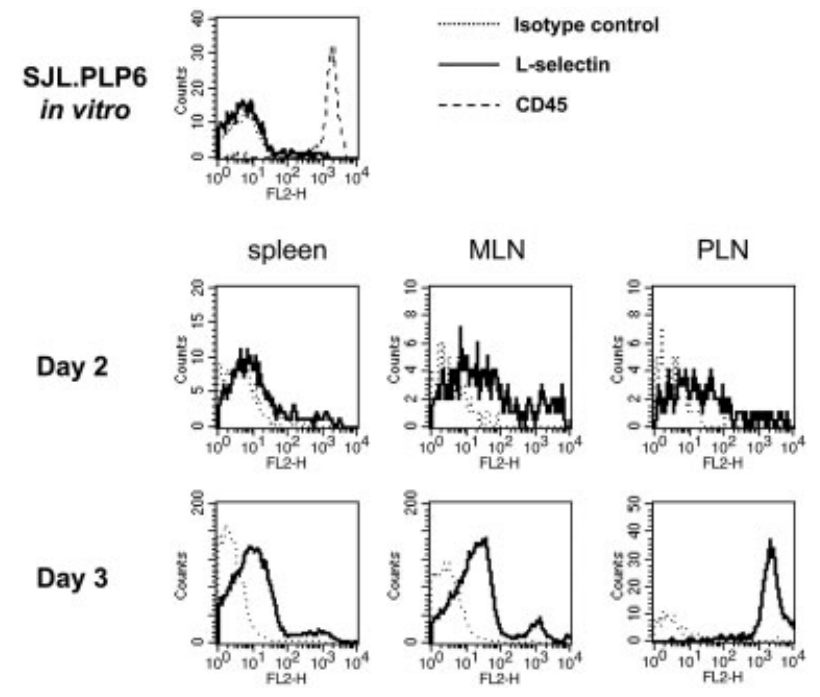

Figure 2. L-selectin is up-regulated on encephalitogenic PLP-specific $\mathrm{T}$ cells in vivo. SJL.PLP6 lymphoblasts were labeled with CellTracker ${ }^{\mathrm{TM}}$ Green directly after restimulation and intravenously injected into SJL mice. In parallel, a small subset of labeled $\mathrm{T}$ cells was cultured in vitro to confirm stability of CellTracker ${ }^{\mathrm{TM}}$ labeling and cell surface phenotype. 48 (day 2) and 72 (day 3) h after injection splenocytes, MLN and PLN cells were harvested and stained for L-selectin using the mAb Mel-14. Cells were scatter gated for live and green fluorescent cells. In contrast to in vitro grown SJL.PLP6, which stained negative for L-selectin, L-selectin expression can be detected on CellTracker ${ }^{\mathrm{TM}}$-positive SJL.PLP6 cells present in spleen, MLN and PLN starting at 2 days after injection. Isotype control staining is shown by a dotted line. One of two independent experiments is shown.
Thus, in vivo a subpopulation of encephalitogenic $\mathrm{T}$ cells originating from the transferred $\mathrm{T}$ cells up-regulates L-selectin cell surface expression. Therefore, L-selectin could indeed contribute to their effector functions required for establishing clinical EAE.

\section{L-selectin-deficient SJL mice develop active EAE}

To study whether EAE can develop in the complete absence of L-selectin, we next asked, if EAE can be actively induced in L-selectin $^{-/-}$SJL mice. Interestingly, we did not observe any difference in the onset, duration or clinical severity of aEAE in L-selectin $^{-/}$SJL mice in backcrossing generations N16-N18 when compared to wild-type control mice (Fig. 3). Thus, in the SJL background L-selectin is not required for the in vivo priming of encephalitogenic $\mathrm{T}$ cells, their trafficking to the CNS or the subsequent molecular mechanisms involved in CNS tissue damage, which all contribute to establish the clinical picture of EAE.

\section{PLP-specific $\mathrm{T}$ cells are primed in the spleen of L-selectin ${ }^{-/-}$SJL mice}

As L-selectin $^{-/-}$SJL mice have dramatically reduced PLN, we next aimed to determine, where PLP-specific $\mathrm{T}$ cells are primed in
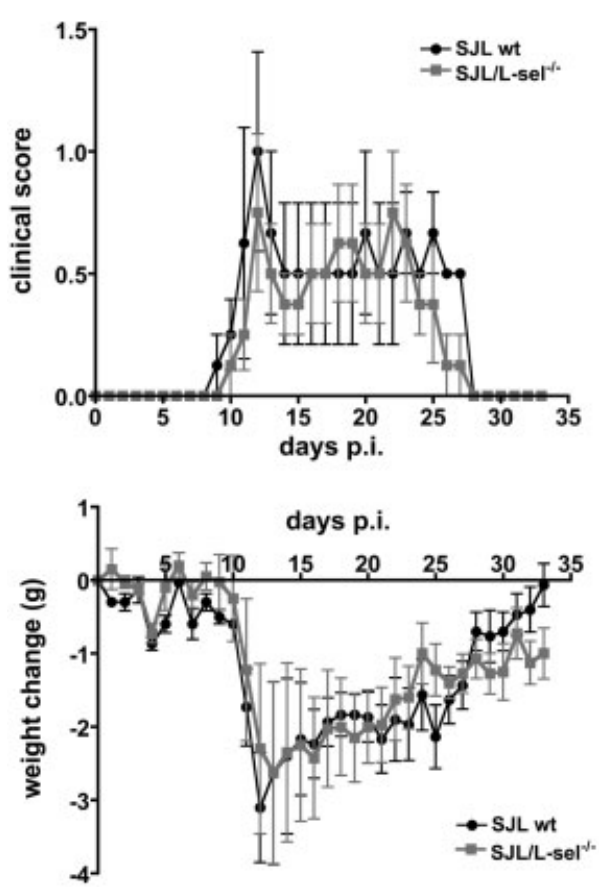

Figure 3. L-selectin-deficient SJL mice develop active EAE indistinguishable from wild-type SJL mice. aEAE was induced in L-selectin ${ }^{-/-}$SJL mice and syngeneic wild-type control mice. Average disease scores \pm SD (top panel) and average weight change \pm SD (bottom panel) assessed daily following immunization with PLPaa139-151 are shown. Values represent three mice per group. One representative experiment out of four with a total number of 22 mice examined per group is shown. 

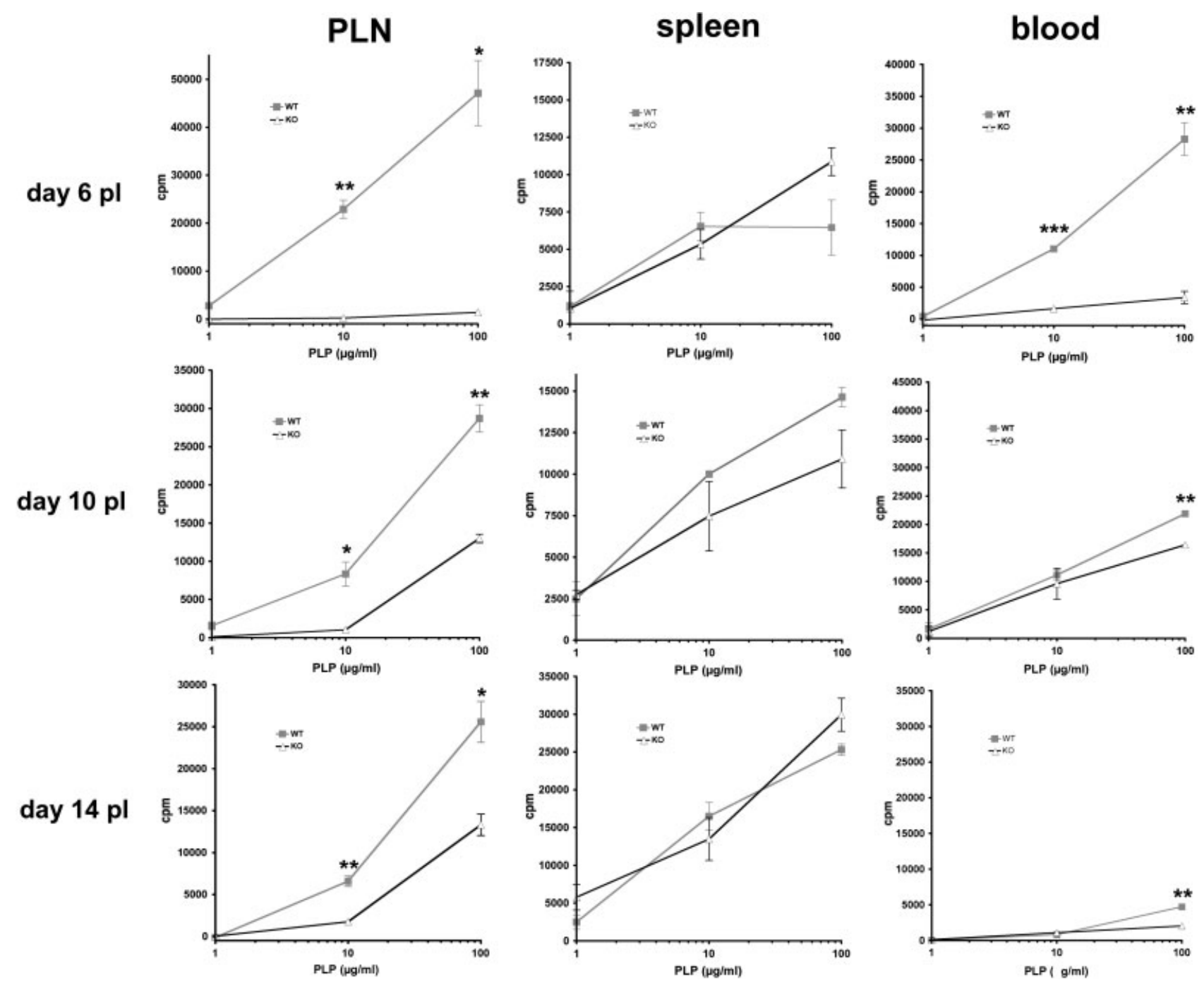

Figure 4. Lack of L-selectin affects the localization of PLP-specific T cell priming in SJL mice. Graphs show PLPaa139-151-induced T cell proliferation in primary cultures of draining PLN, spleen and blood obtained from wild-type (grey lines) and L-selectin ${ }^{-/-}$(black lines) SJL mice at 6, 10 and 14 days p.i. with PLP aa139-151 $_{1}$ CFA for increasing PLP ${ }_{\text {aa139-151 }}$ concentrations in $\mu \mathrm{g} / \mathrm{mL}$. Stimulated proliferation normalized against baseline proliferation in the absence of any stimulus is shown as incorporation of $\left.{ }^{3} \mathrm{H}\right]$ thymidine, values represent mean $\mathrm{cpm} \pm \mathrm{SD}(n=3)$. Compared to wild-type mice, the PLP-specific T cell response is reduced and delayed in PLN and the blood of L-selectin-deficient mice. In contrast, the PLP-specific T cell proliferation observed in splenocyte cultures is comparable in both mice. ${ }^{*} p<0.05,{ }^{* *} p<0.01$.

L-selectin $^{-/-}$versus wild-type SJL mice in vivo after subcutaneous

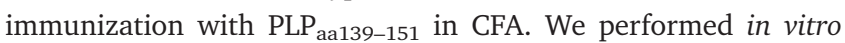
antigen-recall proliferation assays with lymphocytes isolated from draining PLN, spleen and blood. In SJL wild-type mice, a prominent $\mathrm{T}$ cell proliferation response to PLP $\mathrm{Pa}_{\text {139-151 }}$ was detected at 6 days after immunization in the draining PLN and to a lesser degree in the spleen and the blood (Fig. 4). In contrast,

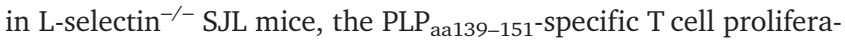
tion was limited to the spleen and maintained there at a comparable level to wild-type mice until the beginning of the disease (day 10 post immunization, p.i.) and during clinical EAE (day 14 p.i.). Although a detectable PLP-specific T cell response is mounted in the PLN of L-selectin ${ }^{-/-}$SJL mice in parallel to the onset of clinical EAE, it remained significantly lower than that observed in PLN of wild-type SJL mice (Fig. 4). To test if the reduced PLP-specific $\mathrm{T}$ cell proliferation observed in PLN of L-selectin $^{-/-}$SJL mice is due to a general proliferation defect of L-selectin-deficient $\mathrm{T}$ lymphocytes, we tested their proliferation to polyclonal stimuli such as Con A and anti-CD3/anti-CD28 stimulation and did not observe any significant difference (data not shown). Once clinical EAE started (day 10 p.i.), a comparable number of PLP-specific T cells was observed in the peripheral blood of both wild-type and L-selectin ${ }^{-1-}$ SJL mice. Thus, in L-selectin $^{-/-}$SJL mice, PLP-specific T cells are predominantly primed in the spleen and later and to a lesser degree in the PLN. Nonetheless, these T cells travel to the CNS at the same time as in wild-type mice since they can be detected in identical amounts in the peripheral blood. 
Ovalbumin-specific $\mathrm{T}$ cells are primed in the spleen of L-selectin $^{-/-}$SJL mice

It has been shown that SJL mice harbor a high frequency of $\mathrm{PLP}_{\mathrm{a}}$ 139-151-specific $\mathrm{T}$ cells due to their escape from central tolerance, as intrathymic expression of PLP is restricted to the shorter splice variant DM20 [19, 20]. Thus, specifically in SJL mice, lack of L-selectin might have less impact on the priming of

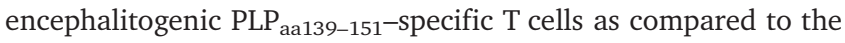

priming of $\mathrm{T}$ cells with other antigen-specificities. We therefore immunized L-selectin-deficient SJL mice and wild-type SJL mice subcutaneously with the model antigen OVA in CFA and compared the in vitro antigen-recall proliferation of OVA-specific $\mathrm{T}$ lymphocytes isolated from the draining PLN and the spleen. Similar to our observations made after immunization with

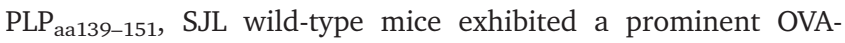
specific T cell proliferative response in the draining PLN and to a lesser degree in the spleen already at 6 days p.i. (Fig. 5). In both

\section{PLN}
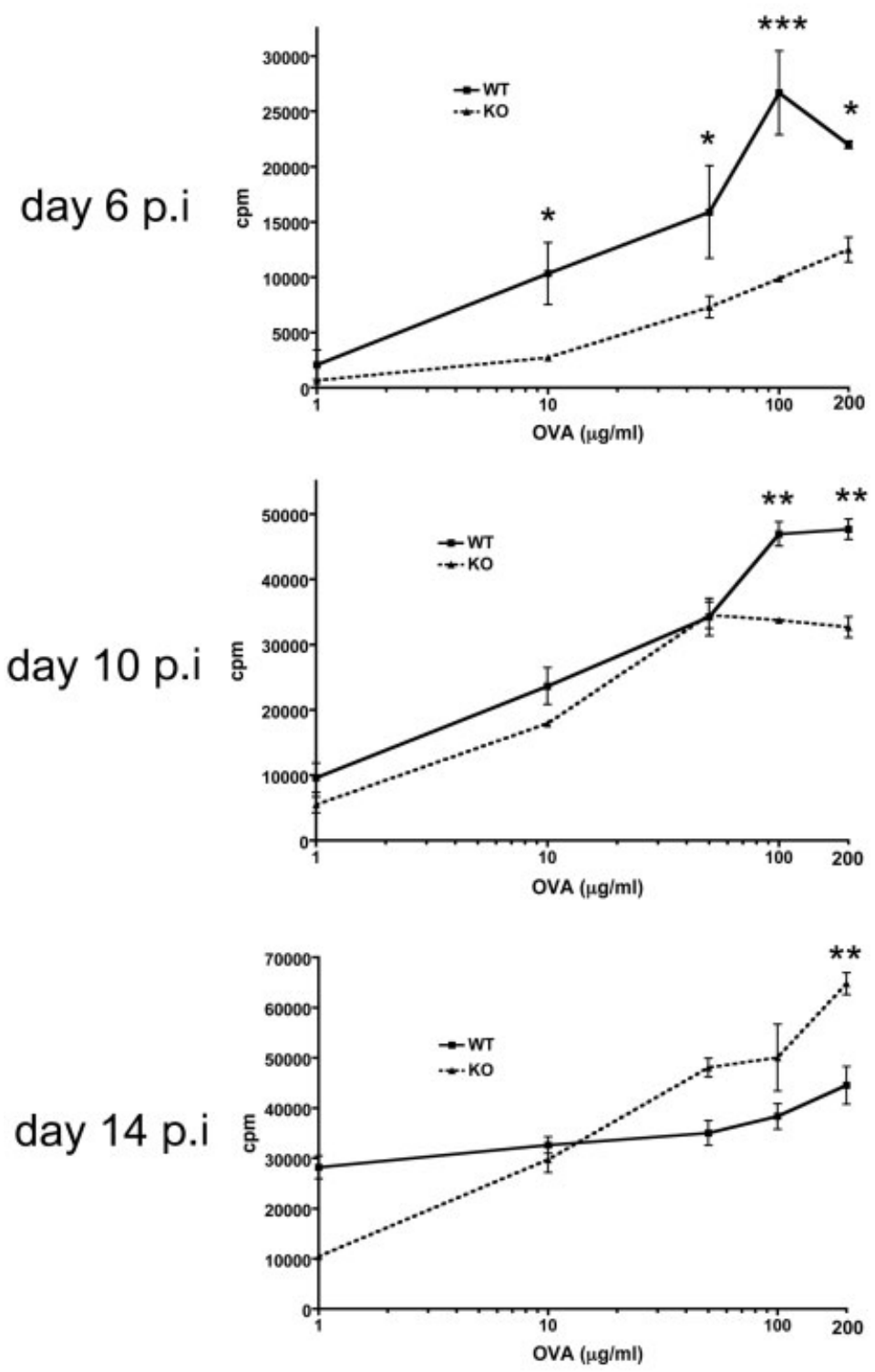

spleen
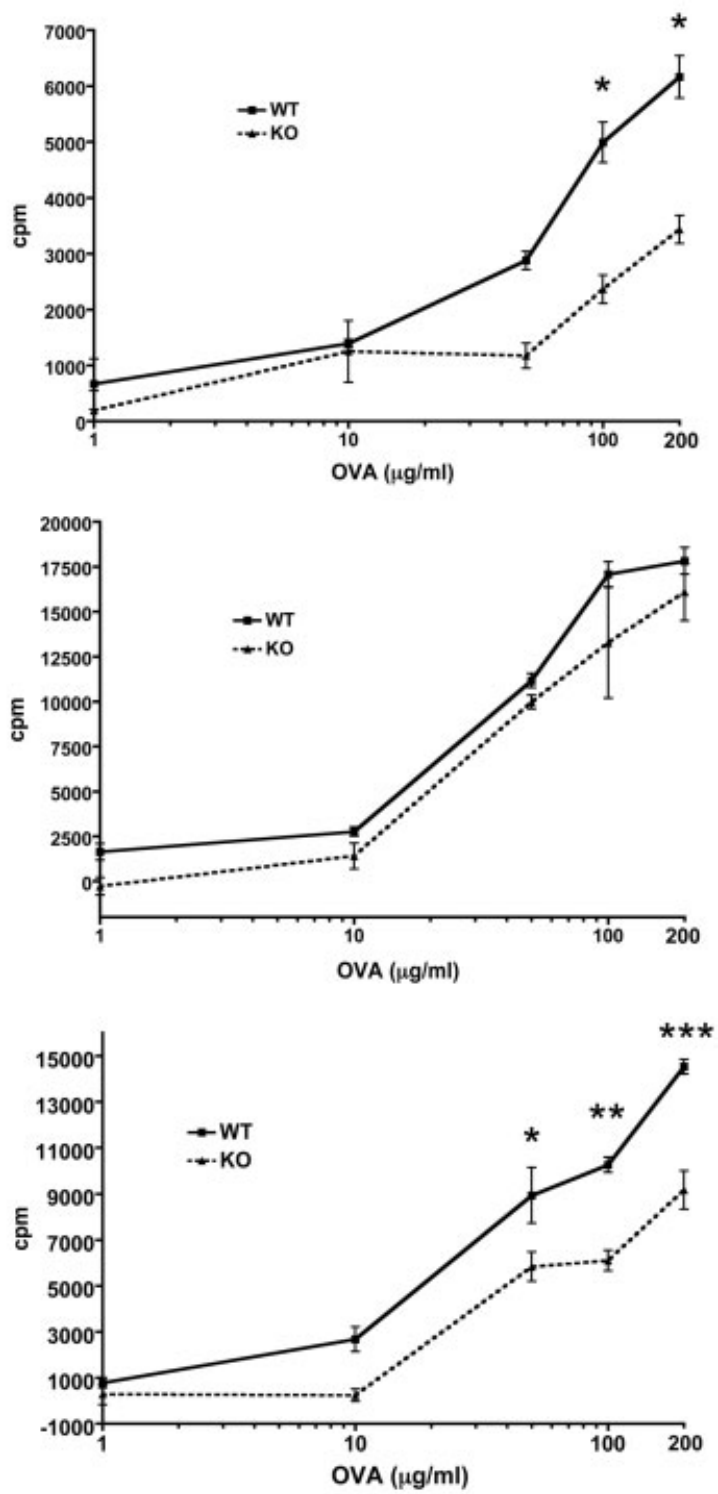

Figure 5. Lack of L-selectin affects the localization of OVA-specific T cell priming in SJL mice. Graphs show OVA-induced T cell proliferation in primary cultures of draining PLN and spleens of wild-type(straight lines) and L-selectin ${ }^{-/}$(dashed lines) SJL mice at 6, 10 and 14 days p.i. with OVA in CFA for increasing OVA concentrations $(\mu \mathrm{g} / \mathrm{mL})$. Proliferation normalized against baseline proliferation in the absence of any stimulus is shown as incorporation of $\left[{ }^{3} \mathrm{H}\right]$ thymidine, values represent mean $\mathrm{cpm} \pm \mathrm{SD}(n=3)$. Compared to wild-type mice, the OVA-specific T cell response is significantly delayed in PLN and spleen of L-selectin ${ }^{-/}$SJL mice, but increasing in both the PLN and the spleen at days 10 and 14 p.i., reaching levels comparable to SJL wild-type mice at day 10 p.i. in the spleen and day 14 p.i. in the PLN. ${ }^{*} p<0.05,{ }^{* *} p<0.01,{ }^{* * *} p<0.001$. 
secondary lymphoid organs the OVA-specific $\mathrm{T}$ cell response further increased at 10 and 14 days p.i. in SJL wild-type mice. In L-selectin $^{-/-}$SJL mice, a significantly reduced OVA-specific T cell proliferation was measured in the PLN and the spleen 6 days after immunization. However, also in ${\mathrm{L}-s e l e c t i n^{-1}}^{-}$SJL mice the OVAspecific $\mathrm{T}$ cell proliferation was found to be increased at 10 and 14 days p.i., reaching comparable levels to the OVA-specific T cell proliferation in SJL wild-type mice. Thus, in L-selectin ${ }^{-/}$SJL mice, priming to a subcutaneously applied model antigen is not generally impaired but rather leads to a compensatory shift of antigen-specific $\mathrm{T}$ cell priming to the enlarged spleens of these mice when compared to SJL wild-type mice.

\section{L-selectin deficient PLP-specific T cells transfer EAE into wild-type and knockout mice}

After identifying the spleen as the immune organ, where antigenspecific T cells are primed in L-selectin ${ }^{-/-}$SJL mice, we set out to investigate whether $\mathrm{L}_{\text {-selectin }}{ }^{-1-}$ PLP-specific $\mathrm{T}$ cell blasts can transfer EAE into wild-type and L-selectin ${ }^{-/-}$SJL mice. We isolated splenocytes from L-selectin ${ }^{-/}$SJL mice subcutaneously immu-

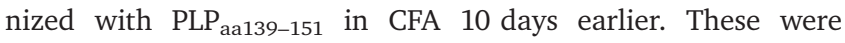
activated with their specific antigen for 4 days in vitro, and $1 \times 10^{7}$ PLP-specific T cell blasts (Fig. 6A) were then intravenously

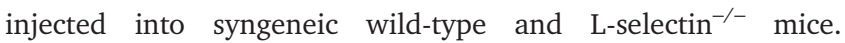
$\mathrm{L}_{\text {-selectin }}{ }^{-/}$PLP-specific $\mathrm{T}$ cells were found to transfer EAE to both wild-type SJL and L-selectin ${ }^{-/}$SJL mice (Fig. 6B). We did not observe any significant difference in the onset, severity or duration of disease. Thus, effector $\mathrm{T}$ cells do not require L-selectin to transfer EAE in the SJL mouse.

\section{L-selectin is not required for inflammatory cell entry into the CNS parenchyma during EAE in the SJL mouse}

Perivascular infiltrates in the brains and spinal cords of EAEresistant $\mathrm{L}-$ selectin $^{-/-}$MBP-TCR transgenic B10.PL mice were found to be restricted to the perivascular space, suggesting that in this model L-selectin is required for extravasation of inflammatory cells across the glia limitans into the CNS parenchyma [9]. We therefore investigated the localization of $\mathrm{CD} 45^{+}$inflammatory cells in the brains of wild-type and L-selectin ${ }^{-/-}$SJL mice during clinical EAE induced either by the transfer of wild-type or L-selectin-deficient PLP-specific T cells. Performing double immunofluorescence staining on frozen brain sections of these mice suffering from EAE demonstrated that independent of the absence or presence of L-selectin on the encephalitogenic T cells or in the host, $\mathrm{CD} 45^{+}$inflammatory cells were able to leave the perivascular space marked by laminin-positive borders (Fig. 7). Furthermore, we did not observe any difference in the size and cellular composition $\left(\mathrm{CD}^{+} \mathrm{T}\right.$ cells, $\mathrm{B}^{+} 20^{+} \mathrm{B}$ cells, Mac- $1^{+}$ macrophages, $\mathrm{CD}^{+}{ }^{+}$T cells) of the inflammatory cuffs in the brains of wild-type and L-selectin ${ }^{-/-}$SJL mice during clinical EAE induced either by the transfer of wild-type or L-selectin-deficient PLP-
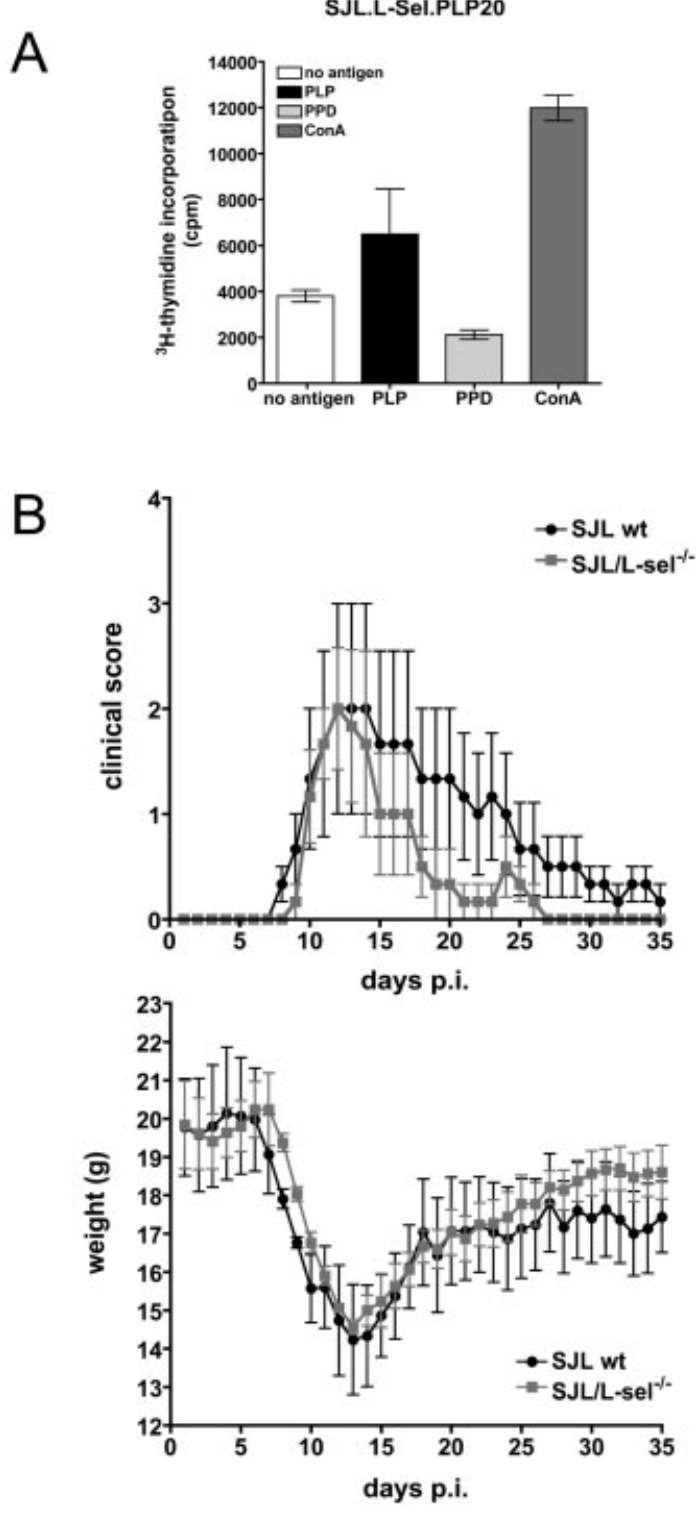

Figure 6. L-selectin-deficient PLP-specific $\mathrm{T}$ cells transfer EAE to syngeneic wild-type and L-selectin-deficient SJL mice. (A) PLP-specific proliferation of L-selectin-deficient $\mathrm{T}$ cells to be used in transfer EAE experiments was ascertained by measuring the incorporation of $\left[{ }^{3} \mathrm{H}\right]$ thymidine in response to $\mathrm{PLP}_{\mathrm{aa139}-151}$, compared to the control protein PPD, the T cell mitogen Con A and medium as a control. Bars represent mean $\pm \mathrm{SD}(n=3)$. (B) L-selectin-deficient PLP-specific T cells transfer EAE into wild-type and L-selectin ${ }^{-/-}$SJL mice. One representative experiment out of 5 with a total number of 20 mice per group examined is shown. The apparently shorter disease duration is not statistically significant.

specific T cells (data not shown). Thus, in SJL mice, L-selectin is neither required for inflammatory cell migration across the endothelial BBB nor for their immigration into the CNS parenchyma. 
SJL.PLP57
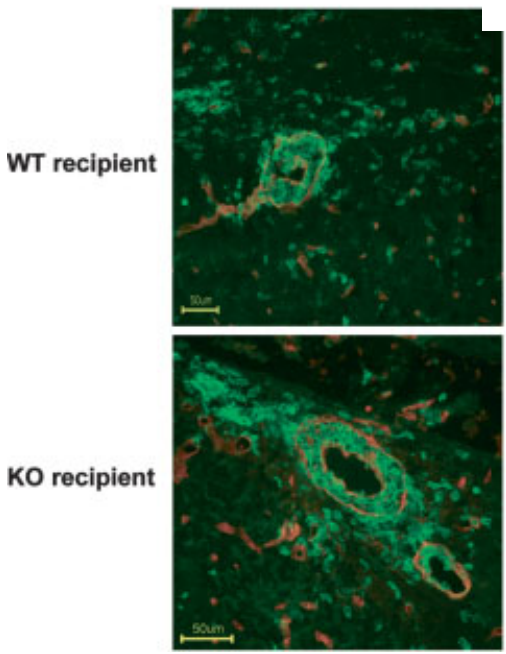

Figure 7. CNS parenchymal infiltration by $\mathrm{CD} 45^{+}$inflammatory cells during EAE is independent of the presence of L-selectin on encephalitogenic $\mathrm{T}$ cells or in the host. Double immunofluorescence staining for CD45 (green) and laminin (red) of frozen brain sections from mice with EAE are shown. Staining demonstrates that the presence of CD $45^{+}$ inflammatory cells outside of the laminin-bordered perivascular space is independent of the transfer of EAE by either wild-type (SJL. PLP57) or L-selectin-deficient (SJL/L-Sel.PLP20) PLP-specific T cells and is also independent of the presence or absence of L-selectin within the host. Bar $50 \mu \mathrm{m}$

\section{L-selectin-deficient C57BL/6 mice develop active EAE}

Based on our present findings that L-selectin is not required for the priming, clonal expansion and effector function of encephalitogenic T cells during EAE in SJL mice, the previous observations that L-selectin-deficient C57BL/ 6 mice are resistant to EAE due to their failure to mount an encephalitogenic $\mathrm{T}$ cells response is quite surprising. Resistance to EAE was observed in L-selectin-deficient C57BL/6 mice in backcrossing generation N10 [8]. To find out whether more extensive backcrossing of L-selectin-deficient mice

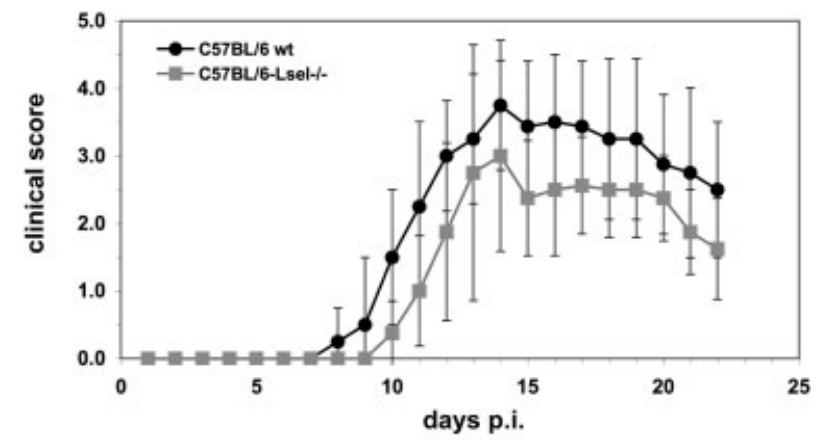

Figure 8. L-selectin-deficient C57BL/6 mice are susceptible to MOGinduced active EAE. aEAE was induced in $\mathrm{L}-$ selectin $^{-1-}$ C57BL/ 6 mice (backcrossing generation N18) and syngeneic wild-type control mice. Average disease scores \pm SD assessed daily following immunization with MOG $_{\text {aa35-55 }}$ are shown. Values represent four mice per group. One representative experiment out of two is shown. into the C57BL/6 background, as performed by us for the SJL mice, has any influence on EAE development, we investigated the development of MOG-induced EAE in L-selectin ${ }^{-/}$C57BL/ 6 mice in backcrossing generation N18. Interestingly, we found that L-selectin ${ }^{-1}$ C57BL/6 mice were susceptible to MOG-induced active EAE (Fig. 8), demonstrating that L-selectin ${ }^{-1-}$ C57BL/6 mice in N18 can mount an encephalitogenic T cell response in the absence of L-selectin.

\section{Discussion}

In this study we demonstrate that the lack of L-selectin does not confer resistance to EAE in the SJL mouse. Our studies with L-selectin $^{-/-}$SJL mice demonstrate that in this model L-selectin is not required for the priming, clonal expansion or effector function of encephalitogenic $\mathrm{T}$ cells, or for inflammatory cell trafficking across the BBB and into the CNS parenchyma during EAE. Transfer EAE studies with wild-type and L-selectin ${ }^{-/-}$SJL mice as recipients, and wild-type and L-selectin ${ }^{-1-}$ PLP-specific T cell lines, confirmed that L-selectin is not needed on encephalitogenic T cells or in the syngeneic recipient for the development of the full clinical and histopathological picture of EAE. Antibody inhibition studies with the anti-L-selectin antibody Mel-14 performed in PLP ${ }_{\text {aa139-151- }}$ induced EAE in the SJL wild-type mouse failed to interfere with the clinical development of EAE, and thus confirm the observations made in the L-selectin ${ }^{-/-}$SJL mouse. Finally, L-selectin ${ }^{-/-}$C57BL/6 mice in backcrossing generation N18 were found to be susceptible to EAE.

Our observations are in apparent contrast to those made in the Lewis rat EAE model, where anti-L-selectin antibodies were shown to suppress EAE induced by immunization with MBP [15]. Interestingly, the very same study demonstrated that anti-Lselectin antibodies do not interfere with EAE induced by the adoptive transfer of encephalitogenic T cells [15], suggesting that blocking of L-selectin in this EAE model targets priming of encephalitogenic $\mathrm{T}$ cells in vivo rather than $\mathrm{T}$ cell trafficking into the CNS. A lack of involvement of L-selectin in T cell migration across the BBB is supported by the findings that Mel-14 does not inhibit the development of clinical EAE induced by transfer of PLPspecific T cells into (PLxSJL) $\mathrm{F}_{1}$ mice due to its failure to block T cell homing to the CNS [7]. The finding that lack of L-selectin does not prevent leukocyte trafficking across the endothelial BBB in general is further supported by active EAE studies performed in MBP-TCR transgenic B10.PL mice [9]. Although B10.PL mice on a L-selectin null background are resistant to clinical EAE, inflammatory cells were still found to accumulate in the brains and spinal cords of these mice after immunization with MBP. Thus, all EAE models investigated have produced evidence that L-selectin is not required for immune cell migration across the BBB.

Interestingly, the perivascular infiltrates observed in the brains and spinal cords of the L-selectin ${ }^{-/-}$MBP-TCR transgenic B10.PL mice [9] remain clinically silent. Such clinically silent perivascular infiltrates limited by the endothelial and the parenchymal basement membranes have been observed before in EAE studies 
performed in C57BL/ 6 mice deficient for matrix metalloproteinases-2 and -9 [21] or for TNF- $\alpha$ [22] and also in the SJL mouse EAE model after depletion of macrophages [23]. In this context it is remarkable that clinical EAE could be induced in the L-selectin $^{-/}$MBP-TCR transgenic B10.PL mice by the adoptive transfer of wild-type macrophages [9], and $\mathrm{F} 4 / 80^{+}$macrophages could then be detected in the CNS parenchyma of these mice. As neither the activation of MPB-specific T cells nor inflammatory cell recruitment across the endothelial $\mathrm{BBB}$ was impaired in the MBPTCR transgenic L-selectin ${ }^{-/-}$B10.PL mice, these observations suggest an involvement of L-selectin in macrophage extravasation to the CNS parenchyma and/or the destruction of myelin during the effector phase of EAE. In this context it is important to note that CNS myelin harbors not-yet-defined L-selectin ligands, which mediate lymphocyte binding in vitro $[24,25]$. The necessity of L-selectin engagement of a myelin ligand as a prerequisite for the development of clinical EAE could, however, neither be observed in L-selectin ${ }^{-1-}$ SJL mice in the present study nor in L-selectin ${ }^{-/-}$ $\mathrm{C} 57 \mathrm{Bl} / 6$ mice [8]. In the latter study performed in the C67BL/6 model it was found that MOG-specific T cells transfer EAE into sublethally irradiated syngeneic recipients independent of the presence or absence of L-selectin on the encephalitogenic T cells or the recipient [8]. These observations are in accordance to those made by us in the SJL mouse, where we did not find any difference in the development of EAE transferred by PLP-specific T cells into syngeneic recipients irrespective of the presence or absence of L-selectin on PLP-specific T cells or in the recipient. A requisite role of L-selectin on macrophages for invasion of the CNS parenchyma during EAE and to mediate myelin damage was thus only observed in MBP-TCR transgenic B10.PL mice, but could not be validated in EAE studies performed in L-selectin ${ }^{-/}$C57Bl/6 or SJL mice. A requirement of L-selectin for the development of clinical EAE may thus be a unique feature of the MBP-TCR transgenic B10.PL mouse model, where monoclonal myelin-specific $\mathrm{T}$ cell activation might overemphasize a role for L-selectin in triggering the effector function of macrophages required to establish clinical EAE.

Due to their lymphocyte homing defect, L-selectin ${ }^{-/-}$mice have dramatically reduced PLN irrespective of their inbred strain background. Thus, an impaired or delayed priming of encephalitogenic $\mathrm{T}$ cells upon induction of active EAE by subcutaneous immunization with myelin antigens in CFA is expected. Surprisingly, L-selectin ${ }^{-1-}$ SJL mice in backcrossing generations N11-N18 did not show any difference in the clinical development of aEAE when compared to wild-type SJL mice. Nevertheless, we found that L-selectin deficiency does indeed compromise the priming of both PLP- and OVA-specific T cells in the PLN. In contrast, antigenspecific T cell proliferation in the spleens of L-selectin ${ }^{-/-}$SJL mice is not affected. Independent of the organ location of their priming, PLP-specific T cells were then detectable in equal amounts in the peripheral blood of both wild-type and L-selectin ${ }^{-/-}$SJL mice at day 10 p.i. right before disease onset. Thus, in the L-selectin ${ }^{-/-}$SJL mouse there is a compensatory shift of PLP-specific T cell priming from PLN to the enlarged spleens, resulting in the lack of any impact on EAE development. Interestingly, in the MBP-TCR B10.PL mice, T cell priming upon immunization with MBP was found to be generally unaffected on the L-selectin ${ }^{-/-}$background in both the spleen but also the PLN [9]. This surprising finding might be due to the unphysiologically high numbers of antigen-specific $\mathrm{T}$ cells already pre-existing in the extremely small PLN of L-selectin ${ }^{-/-}$ MBP-TCR transgenic B10.PL mice. This assumption is supported by the observation that, similar to our observations made in L-selectin $^{-/}$SJL mice, L-selectin ${ }^{-/-}$C57BL/6 mice demonstrate a profound defect in the priming of myelin-specific T cells in the PLN upon induction of active EAE [8]. In contrast to our findings, L-selectin $^{-/-}$C57BL/ 6 mice in backcrossing generations N10 were previously reported to be fully resistant to the induction of active EAE due to their complete failure to mount a MOG-specific T cell response in both the PLN and the spleen [8]. Using L-selectin ${ }^{-1-}$ C57BL/6 mice more extensively backcrossed to the C57BL/6 background (N18), we have found these mice to be quite susceptible to the development of aEAE. Our observations in $\mathrm{L}-$ selectin $^{-/-}$C57BL/ 6 mice (N18) are quite analogous to those in L-selectin $^{-1-}$ SJL mice, where, upon extensive backcrossing (N11-N18), susceptibility of EAE mirrors that of control SJL mice. The apparent discrepancy in susceptibility to EAE in L-selectin $^{-/}$C57BL/6 mice in the previous study compared to our present investigation may thus be attributable to the further backcrossing, subtleties in the EAE induction process, animal housing or other factors.

Taken together, our findings and those by others are in agreement regarding that L-selectin is not required for immune cell migration across the BBB during EAE, irrespective of the EAE model investigated. In the SJL mouse, lack of L-selectin has no impact on the priming, clonal expansion and effector function of encephalitogenic T cells and the development of active or passive EAE. Formally it cannot be excluded that the observed involvement of L-selectin in EAE pathogenesis is due to a closely linked genetic locus modifying L-selectin activity, which could not be separated by backcrossing for 6 or 10 generations as performed in the previous studies. Our observations demonstrating EAE

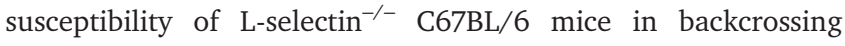
generation N18 support the notion that in higher backcrossing generations absence of L-selectin does not confer protection to aEAE. Finally, it will be important and quite valuable for the interpretation of results obtained in related experimental strategies to find out whether the involvement of L-selectin in triggering effector functions of CNS macrophages during EAE is a unique requirement only observable in an EAE model investigating TCR-transgenic mice.

\section{Material and methods}

\section{Mice}

All animal procedures were performed in accordance with the Swiss and the US legislation on the protection of animals and approved by the respective government authorities. SJL mice were obtained from Taconic (Bomholt, Denmark) and Harlan Winkelmann (Horst, The Netherlands), C57BL/6 mice from Jackson 
Laboratories (Bar Harbor, ME). L-selectin-deficient mice [14] were backcrossed into the EAE susceptible SJL background and used for analysis starting from the 11th backcrossing generation. Most experiments shown in the manuscript were performed with SJL mice in backcrossing generations N15-N18. L-selectin ${ }^{-/-}$C57BL/6 mice were used in backcrossing generation N18.

\section{Genotyping of mice}

The genotype of mice was confirmed by PCR from tail biopsies before and after the experiments. PCR were performed on a Mastercycler ep gradient S (Vaudaux-Eppendorf, Schönenbuch, Switzerland) in $20-\mu \mathrm{L}$ reactions with primers at $0.65 \mu \mathrm{M}$ each, $\mathrm{dNTP}$ at $0.2 \mathrm{mM}, 1 \mathrm{U}$ Taq polymerase (Promega) containing $1 \mu \mathrm{L}$ proteinase K-treated lysates from tail biopsies. PCR cycling was always preceded by a 4-min denaturation step at $94^{\circ} \mathrm{C}$ and followed by a 10 -min final extension step at $72^{\circ} \mathrm{C}$.

Wild type: FW1 5' -TGC CTG GTC CTA GAA CAC TC-3', Rev1 5' GTG GTC CCA CAT CAG CGT AG-3'; PGKneo: FW2 5'-TGT GCC TGG TCC TAG AAC ACT C-3', PGK-Rev2 5'-TGT CAC GTC CTG CAC GAC GC-3'. PCR was conducted for 35 cycles of 45 s. at $94^{\circ} \mathrm{C}, 45 \mathrm{~s}$ at $60^{\circ} \mathrm{C}, 60 \mathrm{~s}$ at $72^{\circ} \mathrm{C}$. The resulting PCR products are $480 \mathrm{bp}$ in size for the wild-type allele and 596 bp for the PGK neo allele.

Primers Tie1-FW3 (5'-CGA AGG GAT GGG AGA GAG AGC-3') and Tie1-Rev2 (5'-TGA CGC TAT GAC GAC GAC GAT G-3') were included in the amplification of an internal control product from the mouse Tie-1 gene.

\section{Peripheral blood and LN lymphocyte counts}

Mice were killed, blood was collected and draining LN and spleen were removed. Single-cell suspensions were produced and cell numbers were determined using the CASY TT Cell counter (Schärfe System, Reutlingen, Germany).

\section{Antibodies}

Anti-mouse CD28 and FITC-conjugated CD45 were purchased from BD Pharmingen (Basel, Switzerland); anti-mouse CD3 $\varepsilon$ was purchased from Milan Analytica AG (La Roche, Switzerland). MEC13.3 (anti-mouse PECAM-1) was a kind gift of Dr. E. Dejana (Milano, Italy). Supernatants of the hybridomas Hermes-1 (9B5, anti-human CD44, used as an isotype-matched control), Mel-14 (anti-L-selectin), M1/9 (anti-mouse CD45), M1/70 (anti-mouse Mac-1), and GK1.5 (anti-mouse CD4) were produced in our own laboratory and used undiluted. For in vivo use endotoxin free antibody preparations were obtained from serum free culture medium by ammonium sulfate precipitation as described before [16]. Polyclonal rabbit anti-laminin antibody (used at 1:200 in immunofluorescence) and rabbit anti-human von WillebrandFactor (vWF) antibody (used at 1:800 in immunofluorescence) were purchased from Dako Diagnostic AG (Zug, Switzerland).

\section{Immunohistology and immunofluorescence}

Mice were anesthetized with isoflurane (Baxter, Arovet AG, Zollikon, Switzerland) and perfused with 1\% paraformaldehyde (Grogg Chemie AG, Stettlen/Deisswil, Switzerland) in PBS through the left ventricle of the heart. Brains and spinal cords were removed, embedded in Tissue-Tek (OCT compound, Haslab, Ostermundingen, Switzerland), snap frozen in an isopentane/dry ice bath (Grogg Chemie AG) and stored at $-80^{\circ} \mathrm{C}$. For immunohistology, cryostat sections $(6 \mu \mathrm{m})$ were air-dried overnight, acetone fixed and stained using a three-step immunoperoxidase staining kit (Vectastain, Reactolab SA, Servion, Switzerland) according to the manufacturer's protocol exactly as described before [3]. For immunofluorescence staining, sections were blocked for 20 min with skimmed milk, incubated for $1 \mathrm{~h}$ each with primary and secondary antibody diluted in skimmed milk, with Tris-buffered saline (TBS) washing steps in between. After a final TBS wash, sections were mounted in Mowiol (Calbiochem, Grogg Chemie AG).

\section{Induction of EAE in SJL mice}

Active EAE was induced by immunizing 8-12-week-old female wild-type and L-selectin-deficient SJL mice with $50 \mu \mathrm{g}$ PLP $_{\text {aa139-151 }}$ in complete Freund's adjuvant (Santa Cruz, LabForce, Nunningen, Switzerland) supplemented with $4 \mathrm{mg} / \mathrm{mL}$ nonviable, desiccated Mycobacterium tuberculosis (H37RA, Difco BD Bioscience Clontech, Allschwill, Switzerland) subcutaneously exactly as described [6]. Per mouse, $3 \times 10^{9}$ attenuated Bordetella pertussis organisms (kindly provided by Crucell-Berna Biotech AG, Bern, Switzerland) were administered intravenously in $0.1 \mathrm{~mL}$ PBS at days 1 and 3 p.i. Passively transferred EAE was induced in SJL mice by intravenous injection of $3 \times 10^{6}$ freshly activated syngeneic encephalitogenic $\mathrm{CD}^{+}{ }^{+}$PLP-specific $\mathrm{T}$ cells or as indicated for the individual experiments $[5,16]$. The PLP-specific Th1 memory/effector T cell lines SJL.PLP2 to SJL.PLP9 raised against the PLP peptide ${ }_{\text {aa139-151 }}$ have been described in detail before $[16,26]$. In agreement with the requirement of the local government, assessment of clinical disease activity was performed twice daily as described before [6] by documenting the clinical severity EAE using a four-point-scoring system as follows: 0, healthy; 0.5, limp tail; 1 , hind leg paraparesis; 2 , hind leg paraplegia; and 3, hind leg paraplegia with incontinence. Note that at clinical score 2 mice are still motile, whereas at clinical score 3 motility of animals begins to be impaired. Additionally, in the SJL EAE model we documented the weight changes during the disease course as we have found this to be a valuable additional measure for disease activity. 


\section{Induction of EAE in $\mathrm{C} 57 \mathrm{BL} / 6$ mice}

Induction of active EAE in C57BL/ 6 was performed exactly as described for SJL mice above, with the sole difference that EAE was induced by subcutaneous immunization of 6-week-old female C57BL/ 6 and L-selectin-deficient C57BL/6 mice (in backcrossing generation N18) with $200 \mu \mathrm{g} \mathrm{MOG}_{\mathrm{aa} 35-55}$ in CFA, supplemented with $4 \mathrm{mg} / \mathrm{mL}$ nonviable, desiccated $M$. tuberculosis. C57BL/6 mice were scored according to their clinical severity as follows: grade 0 , no abnormality; grade 1 , limp tail; grade 2 , limp tail and hind limb weakness (waddling gait); grade 3, partial hind limb paralysis; and grade 4, complete hind limb paralysis.

\section{In vivo homing assays and flow cytometry}

PLP-specific T cell blasts were labeled with $20 \mathrm{nM}$ CellTracker ${ }^{\mathrm{TM}}$ Green in RPMI 1640 with $10 \%$ FBS at $5 \times 10^{6}$ cells $/ \mathrm{mL}$ and $37^{\circ} \mathrm{C}$ for $45 \mathrm{~min}$ exactly as described before [27]. PLP-specific CellTracker ${ }^{\mathrm{TM}}$ Green-labeled T cell blasts $\left(1 \times 10^{7}\right)$ were injected i.v. into syngeneic recipients and spleen, MLN and PLN were harvested at the indicated time points and cell suspensions were prepared. The percentage of CellTracker ${ }^{\mathrm{TM}}$ green-stained T cells in LN and spleen suspension and cell surface expression of L-selectin were analyzed by flow cytometry. FACS analysis for cell surface antigens was performed exactly as described before [5]. Flow cytometric analysis was performed on a FACSCalibur using CellQuest software (Becton Dickinson, Heidelberg, Germany).

\section{$\mathrm{T}$ cell proliferation}

Wild-type and L-selectin-deficient SJL mice were immunized with PLP ${ }_{\text {aa139-151 }}$ exactly as described above omitting injection of B. pertussis organisms. Similarly, immunization with OVA (SigmaAldrich, Switzerland) was performed by subcutaneous injection of $100 \mu \mathrm{g}$ OVA in CFA. At the days indicated, mice were killed, blood was collected and draining LN (popliteal and inguinal) and spleen were removed. Single-cell suspensions were produced and cells were seeded in 96-well plates at $2 \times 10^{5}$ cells/well in RPMI 1640 supplemented with 10\% FBS (GIBCO, LuBiosience, Lucerne, Switzerland), $10 \mathrm{U} / \mathrm{mL}$ penicillin/streptomycin, $2 \mathrm{mM}$ L-glutamine, $1 \%$ nonessential amino acids, $1 \mathrm{mM}$ sodium pyruvate and 0.05 mM $\beta$-mercaptoethanol (Grogg Chemie AG). PLPaa139-151 or OVA diluted in RPMI 1640 was added in increasing concentrations to test for antigen-specific $\mathrm{T}$ cell proliferation. T cell proliferation induced by the mitogen Con $\mathrm{A}(2.5 \mu \mathrm{g} / \mathrm{mL})$ was used as a positive control for $\mathrm{T}$ cell proliferation. All samples were plated in triplicates. $\left[{ }^{3} \mathrm{H}\right]$ Thymidine $(1 \mu \mathrm{Ci} / \mathrm{mL})$ was added $16 \mathrm{~h}$ prior to harvesting the cultures on glass fiber filters using a cell harvester (Inotech, Dottikon, Switzerland) and incorporation of $\left[{ }^{3} \mathrm{H}\right]$ thymidine was measured by liquid scintillation counting.
Acknowledgements: The expert technical assistance of Matthias Meier, Therese Périnat, Patrizia Castiglioni and Mihail Firan is gratefully acknowledged. We thank Dr. Urban Deutsch for critically reading the manuscript. This work was supported by the Max-Planck Society and the University of Bern and partially funded by the Deutsche Forschungsgemeinschaft (SFB 293) and the Swiss National Foundation (grant 3100A0-104096 to BE).

Conflict of interest: The authors declare no financial or commercial conflict of interest.

\section{References}

1 Luster, A. D., Alon, R. and von Andrian, U. H., Immune cell migration in inflammation: Present and future therapeutic targets. Nat. Immunol. 2005. 6: $1182-1190$.

2 Engelhardt, B. and Ransohoff, R. M., The ins and outs of T-lymphocyte trafficking to the CNS: Anatomical sites and molecular mechanisms. Trends Immunol. 2005. 26: 485-495.

3 Engelhardt, B., Kempe, B., Merfeld-Clauss, S., Laschinger, M., Furie, B., Wild, M. K. and Vestweber, D., P-selectin glycoprotein ligand 1 is not required for the development of experimental autoimmune encephalomyelitis in SJL and C57BL/6 mice. J. Immunol. 2005. 175: 1267-1275.

4 Osmers, I., Bullard, D. C. and Barnum, S. R., PSGL-1 is not required for development of experimental autoimmune encephalomyelitis. J. Neuroimmunol. 2005. 166: 193-196.

5 Engelhardt, B., Vestweber, D., Hallmann, R. and Schulz, M., E- and Pselectin are not involved in the recruitment of inflammatory cells across the blood-brain barrier in experimental autoimmune encephalomyelitis. Blood 1997. 90: 4459-4472.

6 Doring, A., Wild, M., Vestweber, D., Deutsch, U. and Engelhardt, B., Eand P-selectin are not required for the development of experimental autoimmune encephalomyelitis in C57BL/6 and SJL mice. J. Immunol. 2007. 179: 8470-8479.

7 Brocke, S., Piercy, C., Steinman, L., Weissman, I. L. and Veromaa, T., Antibodies to CD44 and integrin alpha4, but not L-selectin, prevent central nervous system inflammation and experimental encephalomyelitis by blocking secondary leukocyte recruitment. Proc. Natl. Acad. Sci. USA 1999. 96: 6896-6901.

8 Li, O., Liu, J. Q., Zhang, H., Zheng, P., Liu, Y. and Bai, X. F., CD62L is required for the priming of encephalitogenic T cells but does not play a major role in the effector phase of experimental autoimmune encephalomyelitis. Scand. J. Immunol. 2006. 64: 117-124.

9 Grewal, I. S., Foellmer, H. G., Grewal, K. D., Wang, H., Lee, W. P., Tumas, D., Janeway, C. A. Jr. and Flavell, R. A., CD62L is required on effector cells for local interactions in the CNS to cause myelin damage in experimental allergic encephalomyelitis. Immunity 2001. 14: 291-302.

10 Gallatin, W. M., Weissman, I. L. and Butcher, E. C., A cell-surface molecule involved in organ-specific homing of lymphocytes. Nature 1983. 304: 30-34.

11 Stein, J. V., Cheng, G., Stockton, B. M., Fors, B. P., Butcher, E. C. and von Andrian, U. H., L-selectin-mediated leukocyte adhesion in vivo: Microvillous distribution determines tethering efficiency, but not rolling velocity. $J$. Exp. Med. 1999. 189: 37-50.

12 Ley, K. and Kansas, G. S., Selectins in T-cell recruitment to non-lymphoid tissues and sites of inflammation. Nat. Rev. Immunol. 2004. 4: 325-335. 
13 Xu, J., Grewal, I. S., Geba, G. P. and Flavell, R. A., Impaired primary T cell responses in L-selectin-deficient mice. J. Exp. Med. 1996. 183: 589-598.

14 Catalina, M. D., Carroll, M. C., Arizpe, H., Takashima, A., Estess, P. and Siegelman, M. H., The route of antigen entry determines the requirement for L-selectin during immune responses. J. Exp. Med. 1996. 184: 2341-2351.

15 Archelos, J. J., Jung, S., Rinner, W., Lassmann, H., Miyasaka, M. and Hartung, H. P., Role of the leukocyte-adhesion molecule L-selectin in experimental autoimmune encephalomyelitis. J. Neurol. Sci. 1998. 159: $127-134$.

16 Engelhardt, B., Laschinger, M., Schulz, M., Samulowitz, U., Vestweber, D. and Hoch, G., The development of experimental autoimmune encephalomyelitis in the mouse requires alpha4-integrin but not alpha4beta7-integrin. J. Clin. Invest. 1998. 102: 2096-2105.

17 Baron, J. L., Madri, J. A., Ruddle, N. H., Hashim, G. and Janeway, C. A. Jr., Surface expression of alpha 4 integrin by CD4 T cells is required for their entry into brain parenchyma. J. Exp. Med. 1993. 177: 57-68.

18 Flugel, A., Berkowicz, T., Ritter, T., Labeur, M., Jenne, D. E., Li, Z., Ellwart, J. W. et al., Migratory activity and functional changes of green fluorescent effector cells before and during experimental autoimmune encephalomyelitis. Immunity 2001. 14: 547-560.

19 Klein, L., Klugmann, M., Nave, K. A., Tuohy, V. K. and Kyewski, B., Shaping of the autoreactive T-cell repertoire by a splice variant of self protein expressed in thymic epithelial cells. Nat. Med. 2000. 6: 56-61.

20 Anderson, A. C., Nicholson, L. B., Legge, K. L., Turchin, V., Zaghouani, H. and Kuchroo, V. K., High frequency of autoreactive myelin proteolipid protein-specific $\mathrm{T}$ cells in the periphery of naive mice: Mechanisms of selection of the self-reactive repertoire. J. Exp. Med. 2000. 191: 761-770.

21 Agrawal, S., Anderson, P., Durbeej, M., van Rooijen, N., Ivais, F., Opdenakker, G. and Sorokin, L. M., Dystroglycan is selectively cleaved at the parenchymal basement membrane at sites of leukocyte extravasation in experimental autoimmune encephalomyelitis. J. Exp. Med. 2006. 203: 1007-1019.

22 Korner, H., Riminton, D. S., Strickland, D. H., Lemckert, F. A., Pollard, J. D. and Sedgwick, J. D., Critical points of tumor necrosis factor action in central nervous system autoimmune inflammation defined by gene targeting. J. Exp. Med. 1997. 186: 1585-1590.

23 Tran, E. H., Hoekstra, K., van Rooijen, N., Dijkstra, C. D. and Owens, T., Immune invasion of the central nervous system parenchyma and experimental allergic encephalomyelitis, but not leukocyte extravasation from blood, are prevented in macrophage-depleted mice. J. Immunol. 1998. 161: 3767-3775.

24 Huang, K., Kikuta, A. and Rosen, S., Myelin Localization of a central nervous system ligand for L-selectin. J. Neuroimmunol. 1994. 53: 133-141.

25 Huang, K., Geoffroy, J. S., Singer, M. S. and Rosen, S. D., A lymphocyte homing receptor (L-selectin) mediates the in vitro attachment of lymphocytes to myelinated tracts of the central nervous system. J. Clin. Invest. 1991. 88: 1778-1783.

26 Laschinger, M. and Engelhardt, B., Interaction of alpha4-integrin with VCAM-1 is involved in adhesion of encephalitogenic $\mathrm{T}$ cell blasts to brain endothelium but not in their transendothelial migration in vitro. J. Neuroimmunol. 2000. 102: 32-43.

27 Vajkoczy, P., Laschinger, M. and Engelhardt, B., Alpha4-integrin-VCAM-1 binding mediates $\mathrm{G}$ protein-independent capture of encephalitogenic $\mathrm{T}$ cell blasts to CNS white matter microvessels. J. Clin. Invest. 2001. 108: 557-565.

Abbreviations: aEAE: actively induced EAE - BBB: blood-brain barrier . MBP: myelin basic protein - MLN: mesenteric LN · MOG: myelin oligodendrocyte glycoprotein · p.i.: post immunization · PLN: peripheral LN · PLP: proteolipid protein

Full correspondence: Prof. Britta Engelhardt, Theodor Kocher Institute, University of Bern, Freiestrasse 1, 3012 Bern, Switzerland Fax: +41-31-631-3799 e-mail: bengel@tki.unibe.ch 